\title{
Correction to: 'Test and Treat' Among Women at High Risk for HIV-Infection in Kampala, Uganda: Antiretroviral Therapy Initiation and Associated Factors
}

\author{
Yunia Mayanja $^{1} \cdot$ Onesmus Kamacooko ${ }^{1}$ - Daniel Bagiire ${ }^{1} \cdot$ Gertrude Namale $^{1} \cdot$ Pontiano Kaleebu $^{1} \cdot$ Janet Seeley $^{1,2}$
}

Published online: 6 December 2017

(c) Springer Science+Business Media, LLC, part of Springer Nature 2017

\section{Correction to: AIDS Behav \\ https://doi.org/10.1007/s10461-017-1973-5}

The original version of this article unfortunately contained an error. The incorrect range should be replaced in the second sentence of the Introduction section.
The correct sentence should read as:

These key populations and their sexual partners account for $10-51 \%$ of new infections in sub-Saharan Africa (SSA) [6-8].

The original article has been corrected.

The online version of the original article can be found under https://doi.org/10.1007/s10461-017-1973-5.

Yunia Mayanja

yunia.mayanja@mrcuganda.org

1 MRC/UVRI Uganda Research Unit on AIDS, Plot 51-59

Nakiwogo Road, Entebbe, Uganda

2 London School of Hygiene and Tropical Medicine, London, UK 